\title{
Finite element modeling and simulation of machining of titanium alloy and H13 tool steel using PCBN tool
}

\begin{abstract}
This paper deals with finite element modeling (FEM) and simulation of machining of titanium alloy and H-13 tool steel. Titanium alloys are very suitable for airframe manufacture and aircraft as H-13 uses forging dies and machined die casting. The machinability of both metals was evaluated by high temperature and tool wear. Finite element simulation was performed with ABAQUS explicit software to predict cutting temperature and stress distribution during metal cutting process. The purpose of this study was evaluation the performance of PCBN cutting tool material on machining of titanium alloy and H-13. It was found that PCBN tool can resistant well against high thermal shocks, high temperature and stress distribution when machining difficult to cut materials. The results can give a better understanding of cutting tool material for metal cutting process.
\end{abstract}

Keyword: Finite element modeling; H-13 tool steel; PCBN tool; Titanium alloy 